\title{
SATURATION FLOW ESTIMATION AT SIGNALIZED INTERSECTIONS UNDER MIXED TRAFFIC CONDITIONS
}

\author{
ARPITA SAHA ${ }^{1}$, SATISH CHANDRA ${ }^{2} \&$ INDRAJIT GHOSH ${ }^{3}$ \\ ${ }^{1}$ Department of Civil Engineering, Indian Institute of Technology Roorkee, India \\ ${ }^{2}$ CSIR - Central Road Research Institute, India \\ ${ }^{3}$ Department of Civil Engineering, Indian Institute of Technology Roorkee, India
}

\begin{abstract}
Signalized intersections are one of the major influencing factors for designing an efficient urban road network. Hence, it is necessary to design an efficient intersection. Saturation flow is crucial for designing the signal cycle and the corresponding green phase at an intersection. It is the most fundamental parameter governing capacity of a signalized intersection. But estimation of saturation flow based on field measurements is quite tedious and time-consuming. This difficulty is further aggravated for researchers in developing countries where the traffic condition is highly heterogeneous with almost no lane discipline. In order to address this issue, this paper presents a formula for computing the saturation flow under mixed traffic conditions. The model is presented for the computation of total saturation flow based on road width, the composition of traffic and percentage of right turning vehicles in the approach. Unlike conventional methods, the proposed formula represents saturation flow in vehicles/hr of green/lane to circumvent the tedious job of computing passenger car unit for different types of vehicle at signal controlled intersections.

Keywords: saturation flow, composition, approach width, heterogeneous traffic.
\end{abstract}

\section{INTRODUCTION}

Saturation flow is the maximum number of vehicles that pass the intersection stop line during the green time. According to HCM 2010, saturation flow can be defined as the maximum hourly flow rate at which queued vehicles can cross the intersection under existing traffic condition, assuming that green signal is available all the time and no time loss are experienced by the vehicles. The capacity and level of service of an intersection can be assessed by saturation flow. HCM 2010 has introduced a procedure to estimate saturation flow, assuming that the vehicles follow lane discipline. However, in developing countries like India, traffic is heterogeneous in nature, and very poor lane discipline is maintained. Due to fundamental variation in traffic characteristics and driver behaviour, the models developed in USA and UK for estimating saturation flow are not applicable for developing countries like India. The present study addresses this issue of formulating saturation flow under mixed traffic conditions. In the study, saturation flow was measured in terms of vehicles/ hr of green/ lane instead of PCU/hr of green/lane and thereby reducing the tedious job of computing passenger car unit for an individual vehicle type.

Researchers around the globe came up with a number of studies on saturation flow based on road width, [1]-[3] are few of them [4], also observed a significant increase in the saturation flow rate (measured in PCU per meter width) with an increase in the width of the approach road. [5], proposed a model relating the effect of approach width, turning proportion, the percentage of non-motorized and heavy vehicles on saturation flow. [6], suggested for special attention to the impact of light-duty trucks while analyzing the capacity of a signalized intersection. [7], found that saturation flow rate at signalized intersections in Hanoi and Bangkok is strongly affected by the presence of two wheelers. [8], investigated the effect of travel behaviour of motorcycles on saturation flow in Malaysia and noticed that vehicles follow the first-in-first-out rule at an intersection and it should be considered during 
measurement of saturation flow. Similarly, [9], suggested that capacity and proportion of two wheelers have a linear relationship with positive slope whereas other categories of the vehicles have a negative impact on capacity. Adding to this, [10], observed that left turning and right turning vehicles have a significant effect on saturation flow.

The past studies indicate that road width, traffic composition, turning vehicles have a significant effect on saturation flow estimation. However, all these studies measured and represented saturation flow in terms of PCU/hr of green/lane, ultimately enforced calculation of PCU for different vehicle categories, which in turn make the procedure tedious and complicated. Unlike others, present study measured saturation flow in terms of vehicles $/ \mathrm{hr}$ of green/ lane, can be directly used for estimating delay and degree of saturation of an individual approach. A formula has been proposed for computing saturation flow under mixed traffic conditions based on the composition of traffic stream and percentage of right turning vehicles.

\section{DATA COLLECTION}

Thirteen signalized intersections from Delhi, Chandigarh, Patiala and Punch Kula are chosen for the study. All the intersections were four-legged (provided with channelized left turn lane), right-angled, free from the influence of gradation, parking, bus stops or other side friction. The details of the intersections are presented in Table 1. Data were collected both during the morning (10 a.m. to 1 p.m.) and evening hours (2 p.m. to 5 p.m.). Videography technique was used for collecting data from all the intersections with various approach width. Two cameras were installed to capture an approach. One camera was mounted on the upstream side of the approach; captured the arrival as well as signal timings. One the other hand, second one recorded the departure of vehicles from the downstream end of the approach. A long trap was made to notify the entry and exit of the vehicles at the intersection. The length of the trap was from the stop line of the approach to the end of the queue. End of the queue was decided by visually observing queue length of a number of cycles at the site.

Among 13 intersections, first 7 (I-1 to I-7) were used for formulating the model of saturation flow with traffic composition and turning traffic, the rest 6 (I-8 to I-13) were utilized for validating the formulated relationship.

Table 1: Details of signalized intersections chosen for data collection.

\begin{tabular}{|c|c|c|c|c|}
\hline $\begin{array}{c}\text { Intersection } \\
\text { Number }\end{array}$ & City & $\begin{array}{c}\text { Approach } \\
\text { Width }(\mathrm{m})\end{array}$ & $\begin{array}{c}\text { Cycle Length } \\
(\mathrm{sec})\end{array}$ & $\begin{array}{c}\text { Number of } \\
\text { Observed Cycles }\end{array}$ \\
\hline I-1 & Delhi & 10.2 & 170 & 40 \\
\hline I-2 & Delhi & 10.2 & 170 & 45 \\
\hline I-3 & Patiala & 7.3 & 110 & 50 \\
\hline I-4 & Patiala & 7.3 & 110 & 60 \\
\hline I-5 & Patiala & 8.0 & 120 & 40 \\
\hline I-6 & Chandigarh & 12.1 & 120 & 50 \\
\hline I-7 & Chandigarh & 7.7 & 120 & 60 \\
\hline I-8 & Chandigarh & 14.6 & 180 & 40 \\
\hline I-9 & Chandigarh & 14.3 & 135 & 65 \\
\hline I-10 & Chandigarh & 13.6 & 150 & 40 \\
\hline I-11 & Punch Kula & 8.9 & 100 & 55 \\
\hline I-12 & Punch Kula & 9.1 & 100 & 50 \\
\hline I-13 & Punch Kula & 9.3 & 100 & 65 \\
\hline
\end{tabular}




\section{DATA EXTRACTION AND SATURATION FLOW MEASUREMENT}

Collected video data were extracted, and observed traffic was classified into four categories i.e. two wheelers, three wheelers, cars and heavy vehicles. This classification was based on the size and manoeuvrability characteristics of vehicles. Arrival and departure rate of the vehicles were extracted at every $5 \mathrm{~s}$ interval. Moreover, traffic volume, capacity, and saturation flow are measured. It is to be noted that, present study measured all these parameters in terms of the number of vehicles $(\mathrm{N})$. Saturation flow was measured by plotting a curve of departure/ $5 \mathrm{~s}$ at stop line of the intersection as shown in Fig. 1. The fluctuations in the discharge rate are due to traffic composition. It was observed in the field that at least 2 two wheelers could cross the stop line easily along with a car or a heavy vehicle. In that context, effective green time was measured up to which there were at least three vehicles to discharge. Saturation flow is calculated by using eqn (1).

$$
\mathrm{S}=\frac{\mathrm{N}}{\mathrm{g}_{\mathrm{e}}} \times 3600 \text {. }
$$

Here, $\mathrm{S}=$ Saturation flow (vehicles/ hour of green)

$\mathrm{N}=$ Number of vehicles crossing the stop line during effective green time

$\mathrm{g}_{\mathrm{e}}=$ Effective green time (seconds)

\section{EFFECT OF TRAFFIC COMPOSITION ON SATURATION FLOW}

In the present study, saturation flow was measured in vehicles/ $\mathrm{hr}$ of green and to neutralize the effect of various approach width further converted into vehicles/ hr of green/ lane. To check the effect of different vehicle composition on saturation flow, first seven signalized intersections (I-1 to I-7) were considered. All the approaches have different approach width with channelized left turning lane. Therefore, left turning vehicles do not interfere with through and right turning vehicles. In India, traffic signals are designed such as four phase

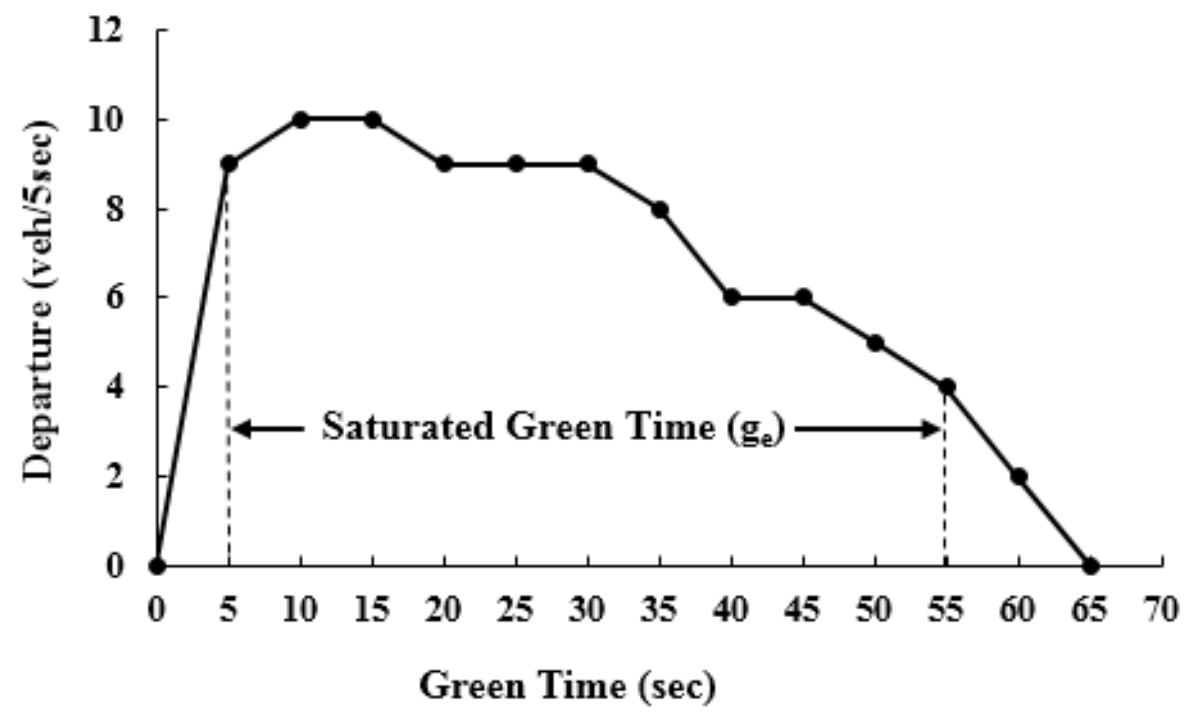

Figure 1: Measurement of saturation flow. 
signals with simultaneous through and right turn movement from an approach. Generally, the right most lane is consistently used by right turning vehicles as no exclusive lane exists for right turners. In that context, the effective width of the approach for through and right turning vehicles need to be determined based on their proportions. It is estimated using eqn 2 . Table 2 shows the effective widths of all the study locations.

$$
\mathrm{W}_{\mathrm{e}}=\frac{\text { Number of } \mathrm{RT} \text { vehicles in a cycle }}{\text { Total vehicles arriving in a cycle }} \times \mathrm{W},
$$

where, $\mathrm{W}_{\mathrm{e}}=$ Effective width for right turning vehicles, $\mathrm{mW}=$ Total approach width, $\mathrm{m}$.

Measured saturation flow was converted into per lane by dividing the effective road width and multiplying by 3.75 . At first, only saturation flow of through moving vehicles was considered and their co-relations with different vehicle categories were carried out. Table 3 indicates that motorized two-wheelers and heavy vehicles have a significant co-relation with through saturation flow

Data of intersection I-1 to I-7 (345 data sets) were taken into account, and a linear regression model (eqn (3)) was developed between through saturation flow $\left(\mathrm{S}_{\mathrm{TH}}\right)$, the proportion of two wheelers $\left(\mathrm{P}_{1}\right)$ and heavy vehicles $\left(\mathrm{P}_{3}\right)$. The model shows that saturation flow of through vehicles linearly increases with an increase in the percentage of motorized two-wheelers and decrease with the share of heavy vehicles. This is mainly due to the size and manoeuvrability of the vehicles. Two- wheelers because of their small size and the better operating condition can squeeze into any gap and reach near the stop line by moving zig-zag. As soon as green signal starts, these vehicles commence in a group and enhance the discharge rate at the stop line for initial few seconds, ultimately leads to a variation of saturation flow. However, heavy vehicles due to their size and manoeuvrability need more green time to cross the stop line and thereby reduces the flow at the stop line.

Table 2: Details of effective width at study locations.

\begin{tabular}{|c|c|c|}
\hline Intersection & $\begin{array}{c}\text { Effective Width for } \\
\text { Through Movement }(\mathrm{m})\end{array}$ & $\begin{array}{c}\text { Effective Width for Right } \\
\text { Turning Movement }(\mathrm{m})\end{array}$ \\
\hline $\mathrm{I}-1$ & 6.27 & 3.93 \\
\hline $\mathrm{I}-2$ & 7.04 & 3.16 \\
\hline $\mathrm{I}-3$ & 3.68 & 3.62 \\
\hline $\mathrm{I}-4$ & 4.84 & 2.46 \\
\hline $\mathrm{I}-5$ & 4.48 & 3.52 \\
\hline $\mathrm{I}-6$ & 6.16 & 5.94 \\
\hline $\mathrm{I}-7$ & 5.23 & 2.47 \\
\hline $\mathrm{I}-8$ & 10.43 & 4.17 \\
\hline $\mathrm{I}-9$ & 10.51 & 3.79 \\
\hline $\mathrm{I}-10$ & 9.70 & 3.90 \\
\hline $\mathrm{I}-11$ & 5.30 & 3.60 \\
\hline $\mathrm{I}-12$ & 5.00 & 4.10 \\
\hline $\mathrm{I}-13$ & 5.45 & 3.85 \\
\hline
\end{tabular}

Table 3: Correlation of saturation flow $\left(\mathrm{S}_{\mathrm{TH}}\right)$ with vehicle composition.

\begin{tabular}{|c|c|c|c|c|}
\hline & \% Two-Wheeler $\left(\mathrm{P}_{1}\right)$ & \% Car $\left(\mathrm{P}_{2}\right)$ & \% Heavy Vehicle $\left(\mathrm{P}_{3}\right)$ & \% Three-Wheeler $\left(\mathrm{P}_{4}\right)$ \\
\hline $\mathrm{S}_{\text {TH }}$ & 0.85 & 0.23 & -0.79 & 0.16 \\
\hline
\end{tabular}




$$
\begin{gathered}
\mathrm{S}_{\mathrm{TH}}=1395+35 \times \mathrm{P}_{1}-61 \times \mathrm{P}_{3}, \\
(15.29)(10.61)
\end{gathered}
$$

where, $\mathrm{S}_{\mathrm{TH}}=$ Saturation flow of through moving vehicles in a cycle (veh/hr of green/lane) $\mathrm{P}_{1}=$ Proportion of motorized two-wheelers in through traffic stream of a cycle $(\%)$ $\mathrm{P}_{3}=$ Proportion of motorized heavy vehicles in through traffic stream of a cycle (\%) Values given in parenthesis are the ' $t$ ' statistic of coefficients which are greater than the tabulated value at $95 \%$ level of confidence.

The measured saturation flow was validated with respect to estimated saturation flow using eqn (3). Data of intersection I-8 to I-13 was used for validation purpose. Fig. 2 shows the plot between saturation flows obtained from field data and calculated using the model. It indicates that all the data points are near to $45^{\circ}$ line. In addition to this, there is a good match between field-measured and modelled saturation flow with a maximum difference of $8 \%$. Therefore, the model can be successfully used for accurate estimation of saturation flow at similar type of intersections with heterogeneous traffic.

\section{EFFECT OF TURNING MOVEMENT ON SATURATION FLOW}

According to [10] and [2], while crossing, all through, left and right turning vehicles significantly affect the saturation flow of an intersection approach. At all the study intersections, left turn was channelized, but no separate lanes were provided for right turning vehicles. So right turning and through vehicles were moving together in the same green phase. Eqn (3) models the saturation flow for through moving vehicles only considering the proportion of small and heavy vehicles. Therefore, an attempt was made to check how the movement of turning vehicles effect saturation flow of an intersection approach. In that regard, total discharge $(\mathrm{TH}+\mathrm{RT})$ at the stop line was observed for all the seven intersections (I-1 to I-7) and variations with the proportion of right turners, and through saturation flow were noted. Based on the variations, eqn (4) was proposed

$$
\mathrm{S}_{\mathrm{Total}}=\mathrm{S}_{\mathrm{TH}}+34 \times \mathrm{P}_{\mathrm{RT}}
$$

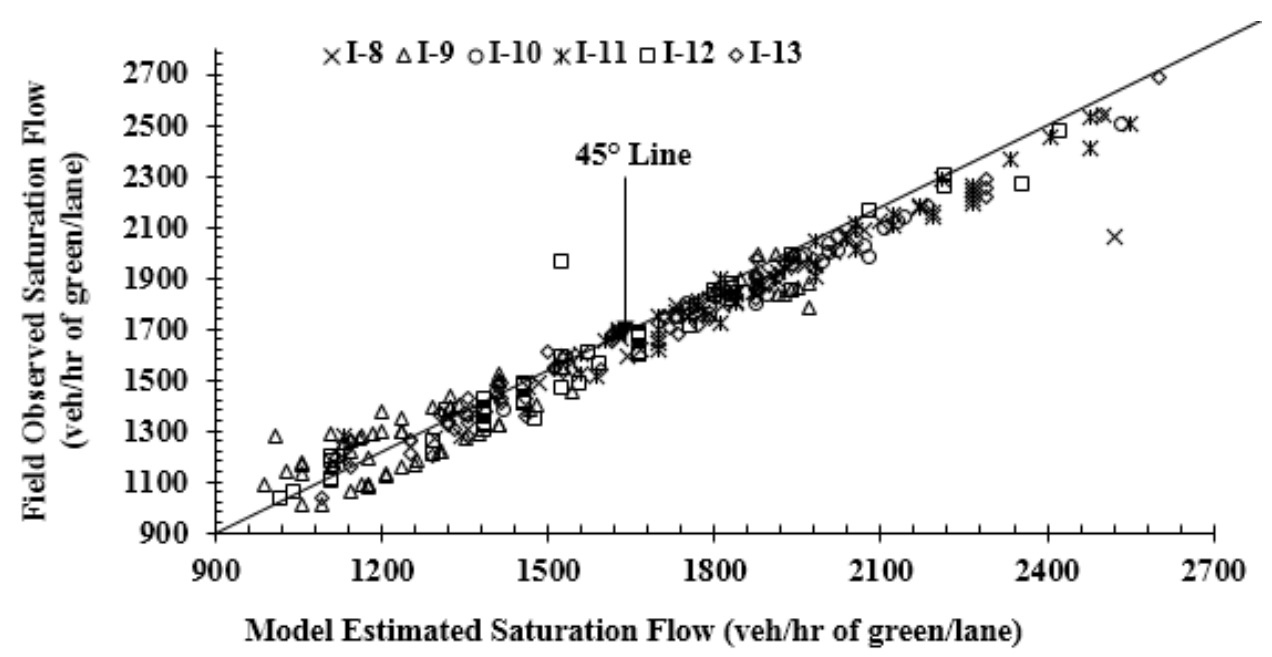

Figure 2: Validation of proposed saturation flow model for through stream. 
Substituting the value of $\mathrm{S}_{\mathrm{TH}}$ from eqn (3):

$$
\mathrm{S}_{\text {Total }}=1395+35 \times \mathrm{P}_{1}-61 \times \mathrm{P}_{3}+34 \times \mathrm{P}_{\mathrm{RT}},
$$

where, $\mathrm{S}_{\text {Total }}=$ Total saturation flow of an intersection approach (veh/hr of green/lane)

$\mathrm{S}_{\mathrm{TH}}=$ Saturation flow of through moving vehicles of a cycle $(\mathrm{veh} / \mathrm{hr}$ of green/lane)

$\mathrm{P}_{\mathrm{RT}}=$ Proportion of right turning vehicles in the approach (\%)

Equation (5) can be used for estimating saturation flow when both right turning and through moving vehicles share the approach at a same time. Whereas, eqn (3) can be utilized for determining the saturation flow of an approach with through vehicles only. It was observed from the proposed models that not only traffic composition but the proportion of right turning vehicles also have a significant effect on the estimation of saturation flow. Fig. 3 shows that eqn (5) can be successfully used for estimating the total saturation flow of study intersections I-8 to I-13 (which were not used for development of the model) with a maximum error of $9.5 \%$, which is quite acceptable.

\section{CONCLUSION}

In developing countries traffic is heterogeneous in nature, no separate lanes are dedicated to the turning movements as well as poor lane discipline is maintained. Therefore, at intersections situation became chaotic while crossing the stop line as heavy vehicles and cars need to compete with two and three wheelers to get their turn. To deal with the effect of heterogeneity, the present study came up with a model of estimating saturation flow in terms of vehicles/hr of green/lane. The model estimates total saturation flow based on the composition of through traffic and percentage of right-turning traffic in the approach.

In this regard data from thirteen signalized intersections of four different cities were considered. Data of intersections I-1 to I-7 were used for formulating the model and for validation purpose intersection I- 8 to I-13 were considered. The validation showed that field observed saturation flow values were pretty much similar with the model estimated values. However, maximum difference was $8-10 \%$ which is in an acceptable limit. Therefore, it can be recommended that saturation flow measurement of an intersection approach can be done in terms of vehicles/hr of green/lane as well and the proposed models can be successfully used for saturation flow measurement at intersection locations under mixed traffic conditions.

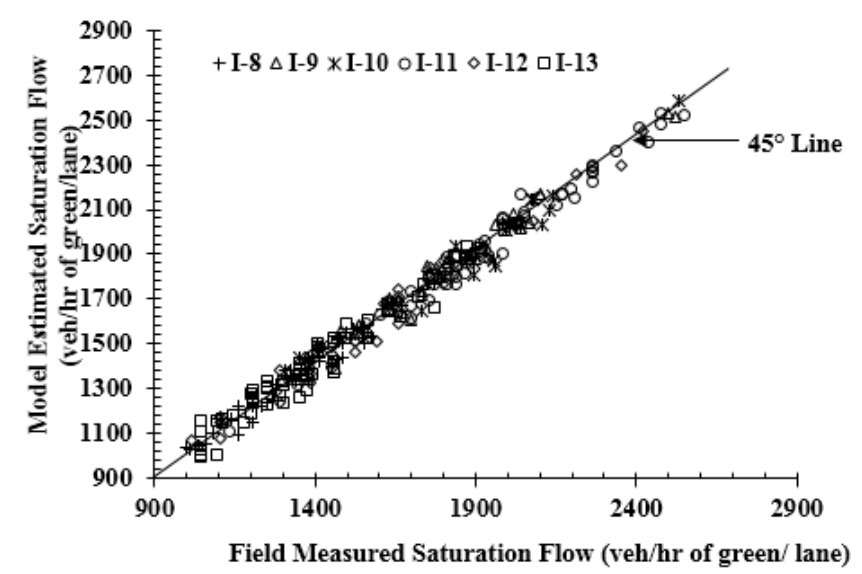

Figure 3: Validation of proposed total saturation flow model. 


\section{REFERENCES}

[1] Webster, F.V. \& Cobbe, B.M.,Traffic Signals, Road Research Technical Paper, Road Research Laboratory 56, Her Majesty's Station. Office London, 1966.

[2] Bhattacharya, A.K. \& Bhattacharya, P.G., Observation and analysis of saturation flow through signalized intersection in Calcutta, Indian Highways, 10, pp. 11-33, 1982.

[3] Susilo, B.H. \& Solihin, Y., Modification of saturation flow formula by width of road approach, Procedia Social and Behavioral Science, 16, pp. 620-629, 2011.

[4] Arasan, V.T. \& Vedagiri, P., Estimation of saturation flow of heterogeneous traffic using computer simulation, Proceeding of 20th European Conference on Modelling and Simulation, 2006.

[5] Hossain M., Estimation of saturation flow at signalised intersections of developing cities : a micro-simulation modelling approach, Transportation Research: Part A, 35, pp. 123-141, 2001.

[6] Kockelman, K.M. \& Shabih, R.A., Effect of light-duty trucks on the capacity of signalized intersections, Journal of Transportation Engineering, 126(6), pp. 506-512, 2000.

[7] Minh, C.C. \& Sano, K., Analysis of motorcycle effects to saturation flow rate at signalized intersection in developing countries, Journal of Eastern Asia Society of Transportation Studies, 5, pp. 1211-1222, 2003.

[8] Vien, L.L., Wan Ibrahim, W.H. \& Mohd, A.F., Effect of motorcycles travel behaviour on saturation flow rates at signalized intersections in Malaysia, 23rd ARRB Conference on Research Partnering with Practice, pp. 1-11, 2008.

[9] Anusha, C., Verma, A. \& Kavita, G., Effect of two-wheelers on saturation flow at signalized intersections in developing countries, Journal of Transportation Engineering, 139(5), pp. 448-457, 2012.

[10] Leong, H.J.N., Some aspects of urban intersection capacity, Proceedings of $2^{\text {nd }} A R R B$ Conference, Australia, 21, pp. 305-338, 1964. 